\title{
Concentrations of trace elements in marine fish and its risk assessment in Malaysia
}

\begin{abstract}
Concentrations of trace elements (V, Cr, Mn, Co, Cu, Zn, Ga, Se, Rb, Sr, Mo, Ag, Cd, Sn, $\mathrm{Sb}, \mathrm{Cs}, \mathrm{Ba}, \mathrm{Hg}, \mathrm{Tl}, \mathrm{Pb}$ and $\mathrm{Bi}$ ) were determined in muscle and liver of 12 species of marine fish collected from coastal areas in Malaysia. Levels of V, Cr, Mn, Co, Cu, $\mathrm{Zn}, \mathrm{Ga}, \mathrm{Sr}, \mathrm{Mo}$, $\mathrm{Ag}, \mathrm{Cd}, \mathrm{Sn}, \mathrm{Ba}$ and $\mathrm{Pb}$ in liver were higher than those in muscle, whereas $\mathrm{Rb}$ and $\mathrm{Cs}$ concentrations showed the opposite trend. Positive correlations between concentrations in liver and muscle were observed for all the trace elements except $\mathrm{Cu}$ and $\mathrm{Sn}$. Copper, $\mathrm{Zn}, \mathrm{Se}$, $\mathrm{Ag}, \mathrm{Cd}, \mathrm{Cs}$ and $\mathrm{Hg}$ concentrations in bigeye scads from the east coast of the Peninsular Malaysia were higher than those from the west, whereas V showed the opposite trend. The high concentration of $\mathrm{V}$ in the west coast might indicate oil contamination in the Strait of Malacca. To evaluate the health risk to Malaysian population through consumption of fish, intake rates of trace elements were estimated on the basis of the concentrations of trace elements in muscle of fish and daily fish consumption. Some specimens of the marine fish had $\mathrm{Hg}$ levels higher than the guideline value by US Environmental Protection Agency (EPA), indicating that consumption of these fish at the present rate may be hazardous to Malaysian people. To our knowledge, this is the first study on multielemental accumulation in marine fish from the Malaysian coast. (C) 2005 Elsevier Ltd. All rights reserved.
\end{abstract}

Keyword: Malaysia; Marine fish; Mercury; Risk assessment; Trace elements; Vanadium 